\title{
Order Fulfillment Performance Evaluation in Supply Chain Management Under Intuitionistic Fuzzy Environment
}

\author{
Serhat $\operatorname{Aydun}^{a}$ and Cengiz Kahraman ${ }^{b}$ \\ ${ }^{a}$ Department of Industrial Engineering, National Defense University Air Force Academy, 34149, Yeşilyurt, \\ Bakırköy, Istanbul, TURKEY, saydin3@hho.edu.tr \\ ${ }^{\mathrm{b}}$ Department of Industrial Engineering, Istanbul Technical University, 34367, Maçka, Beşiktaş, Istanbul, \\ TURKEY, kahramanc@itu.edu.tr
}

\begin{abstract}
Supply chain management process includes many activities to transform raw materials into final products considering with customer satisfaction. Order fulfillment process is one of them and plays a critical role in ensuring customer satisfaction. This study proposes uncertain dynamic intuitionistic decision making method in order to evaluate order fulfillment performance. The method uses intervalvalued intuitionistic fuzzy numbers and simple calculation operators. Three firms are evaluated according to seven criteria, and a sensitivity analysis is conducted to show the robustness of the model. We conclude that the method is a useful tool for handling multi-period decision making problems in the intuitionistic fuzzy environment.
\end{abstract}

Keywords: Supply chain management, order fulfillment, uncertain dynamic intuitionistic fuzzy MCDM.

\section{Introduction}

Supply chain management is the integration of key business processes (Customer relationship management, supplier relationship management, customer service management, demand management, order fulfillment, manufacturing flow management, product development and commercialization, returns management) from end user through original suppliers that provides products, services, and information that add value for customer and other stakeholders [1].

Order fulfillment process is one of the key processes in supply chain management and the term is used to define generating, filling, delivering, and servicing customer orders [2]. Due to the developing technology and customer requests, time management is the crucial point for the firms. Successful management of the order fulfillment process can decrease the delivery time and provide customer satisfaction.

Order fulfillment process of the firm should respond customers' demand while staying within the budget limitations. Managers in charge of running the order fulfillment process should understand the requirements of the customers and take these requirements into order fulfillment process management. In other words, managers should design a network between customers and firms. In this point, order fulfillment process management is strategic decision making for the firms.

Managers need to measure order fulfillment process performance in order to learn how well their firm is performing the process, analyze the process periodically and improve it, or measure their partners order fulfillment performance. Measuring performance process includes two main steps namely; which metrics will be used and which method will be used.

Multi criteria decision making (MCDM) methods have been used as a useful tool in many fields, such as engineering [3], risk management [4], technology $[5,6]$, supply chain management $[7,8]$, and so on. Performance assessment problem contains both qualitative and quantitative factors; therefore, it needs experts' judgments. Due to the shortcomings incurred by the subjectivity of human judgments and vagueness of data, the ordinary fuzzy set theory, developed by Zadeh [9], can be used in performance assessment decision making processes. In the literature ordinary fuzzy set theory and MCDM methods are combined such as; Fuzzy AHP [10,11], fuzzy ELECTRE [12], fuzzy ANP [13], fuzzy DEMATEL[14], fuzzy TOPSIS [15].

In recent years, ordinary fuzzy sets have been extended to new types and intuitionistic fuzzy set (IFSs), developed by Atanassov [16] is one of these extensions. IFSs include the membership value as well as the non-membership value and carry more information than ordinary fuzzy sets. Therefore, IFSs 
has been used in many MCDM problems [17,18,19]. In this paper, we focus on uncertain dynamic Intuitionistic fuzzy MCDM [20] to assess firms' order fulfillment performance process.

The rest of the paper is organized as follows: In Section 2 the details of uncertain dynamic intuitionistic fuzzy MCDM decision making method is explained. A case study and sensitivity analysis are presented in Section 3. Finally, conclusions are presented in Section 4.

\section{Uncertain Dynamic Intuitionistic Fuzzy Multi Attribute Decision Making}

In this section, we consider uncertain dynamic intuitionistic fuzzy MCDM problems where all the attribute values are expressed in interval-valued intuitionistic fuzzy numbers (IVIFNs), which are collected at different periods of time. $\mathrm{Xu}$ and Yager [20] proposed uncertain dynamic intuitionistic fuzzy MCDM method as follows:

\subsection{Preliminaries}

Let a set $Z$ be fixed, and IVIFN $\tilde{A}$ over $Z$ is an object having the form.

$$
\tilde{A}=\left\{z, \tilde{\mu}_{\tilde{A}}(z), \tilde{v}_{\tilde{A}}(z) z \in Z\right\}
$$

Where $\tilde{\mu}_{\tilde{\mathrm{A}}}(\mathrm{z})=\left[\mu_{\tilde{\mathrm{A}}}^{\mathrm{L}}(\mathrm{z}), \mu_{\tilde{\mathrm{A}}}^{\mathrm{U}}(\mathrm{z})\right] \subset[0,1]$ and

$$
\tilde{\mathrm{v}}_{\tilde{\mathrm{A}}}(\mathrm{z})=\left[\mathrm{v}_{\tilde{\mathrm{A}}}^{\mathrm{L}}(\mathrm{z}), \mathrm{v}_{\tilde{\mathrm{A}}}^{\mathrm{U}}(\mathrm{z})\right] \subset[0,1] \text { are intervals }
$$

$\mu_{\tilde{\mathrm{A}}}^{\mathrm{L}}(\mathrm{z})=\inf \tilde{\mu}_{\tilde{\mathrm{A}}}(\mathrm{z}), \mu_{\tilde{\mathrm{A}}}^{\mathrm{U}}(\mathrm{z})=\sup \tilde{\mu}_{\tilde{\mathrm{A}}}(\mathrm{z})$,

$$
v_{\tilde{A}}^{L}(z)=\inf _{\tilde{\tilde{A}}}(z), \quad v_{\tilde{A}}^{U}(z)=\sup \tilde{v}_{\tilde{A}}(z) \text { ， }
$$

and for every $\mathrm{z} \in \mathrm{Z}$ :

$$
\mu_{\tilde{\mathrm{A}}}^{\mathrm{U}}(\mathrm{z})+\mathrm{v} \tilde{\mathrm{A}}(\mathrm{z}) \leq 1
$$

Let $\tilde{\pi}_{\tilde{\mathrm{A}}}(\mathrm{z})=\left[\pi_{\tilde{\mathrm{A}}}^{\mathrm{L}}(\mathrm{z}), \pi_{\tilde{\mathrm{A}}}^{\mathrm{U}}(\mathrm{z})\right]$, where

$\pi_{\tilde{\mathrm{A}}}^{\mathrm{L}}(\mathrm{z})=1-\mu_{\tilde{\mathrm{A}}}^{\mathrm{U}}(\mathrm{z})-\mathrm{V}_{\tilde{\mathrm{A}}}^{\mathrm{U}}(\mathrm{z}), \pi_{\tilde{\mathrm{A}}}^{\mathrm{U}}(\mathrm{z})=1-\mu_{\tilde{\mathrm{A}}}^{\mathrm{L}}(\mathrm{z})-\mathrm{V} \tilde{\mathrm{A}}(\mathrm{z})$

For convenience, we denote an IVIFN by $\tilde{\alpha}=\left(\tilde{\mu}_{\tilde{\mathrm{a}}}, \tilde{\mathrm{v}}_{\tilde{\mathrm{a}}}, \tilde{\pi}_{\tilde{\mathrm{a}}}\right)$, Let $t$ be a time variable, then we call $\tilde{\alpha}(\mathrm{t})=\left(\left[\mu_{\tilde{\alpha}(t)}^{\mathrm{L}}, \mu_{\tilde{\alpha}(t)}^{\mathrm{U}}\right],\left[\mathrm{v}_{\tilde{\alpha}(\mathrm{t})}^{\mathrm{L}}, \mathrm{v}_{\tilde{\alpha}(t)}^{\mathrm{U}}\right],\left[\pi_{\tilde{\alpha}(t)}^{\mathrm{L}}, \pi_{\tilde{\alpha}(t)}^{\mathrm{U}}\right]\right)$ an uncertain intuitionistic fuzzy variable, then $\tilde{\alpha}\left(t_{1}\right), \tilde{\alpha}\left(t_{2}\right), \ldots, \tilde{\alpha}\left(t_{n}\right)$ denote $p$ IVIFNs collected at $p$ different periods.

\subsection{Uncertain dynamic intuitionistic fuzzy MCDM}

Step 1. Determine the criteria, the criteria weights and periods' weights.
Step 2. Evaluate the alternatives with IVIFNs and create uncertain intuitionistic fuzzy decision matrices for different periods.

Step 3. Use uncertain dynamic weighted fuzzy averaging (UDIFWA) operator in order to aggregate the performances at different periods.

$\operatorname{UDIFWA}_{\alpha_{\mathrm{HU}}}\left(\tilde{\alpha}(\mathrm{t})=\tilde{\alpha}\left(\mathrm{t}_{1}\right), \tilde{\alpha}\left(\mathrm{t}_{2}\right), \ldots, \tilde{\alpha}\left(\mathrm{t}_{\mathrm{p}}\right)\right)=$

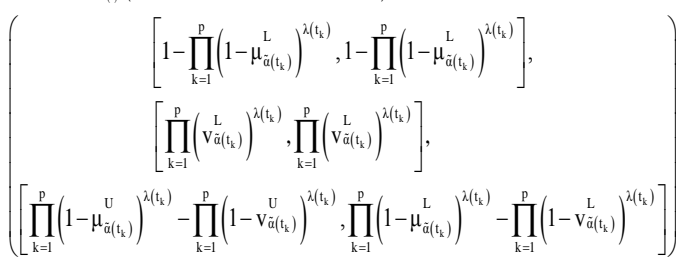

UDIFWA operator aggregates all the uncertain intuitionistic fuzzy decision matrices for different periods into a complex uncertain intuitionistic fuzzy decision matrix.

Step 4. Define $\tilde{\alpha}^{+}=\left(\tilde{\alpha}_{1}^{+}, \tilde{\alpha}_{2}^{+}, \ldots, \tilde{\alpha}_{\mathrm{m}}^{+}\right)^{T} \quad$ and $\tilde{\alpha}^{-}=\left(\tilde{\alpha}_{1}^{-}, \tilde{\alpha}_{2}^{-}, \ldots, \tilde{\alpha}_{m}^{-}\right)^{T}$ as the uncertain intuitionistic fuzzy ideal solution and the uncertain intuitionistic fuzzy negative ideal solution, respectively, where $\tilde{\alpha}^{+}=([1,1],[0,0],[0,0])(\mathrm{i}=1,2, \ldots, \mathrm{m})$ are the $m$ largest IVIFNs, and $\tilde{\alpha}^{-}=([0,0],[1,1],[0,0])(\mathrm{i}=1,2, \ldots, \mathrm{m})$ are the $m$ smallest IVIFNs.

Step 5. Calculate the distance between the alternative $\mathrm{A}_{i}$ and the uncertain intuitionistic fuzzy ideal solution, and the distance between $\mathrm{A}_{i}$ and intuitionistic fuzzy negative ideal solution as follows:

$$
\begin{aligned}
& \mathrm{d}\left(A_{\mathrm{i}}, \tilde{\alpha}^{+}\right)=\frac{1}{2} \sum_{\mathrm{j}=1}^{\mathrm{m}} \mathrm{w}_{\mathrm{j}}\left[2-\left(\mu_{\mathrm{ij}}^{\mathrm{L}}+\mu_{\mathrm{ij}}^{\mathrm{U}}\right]\right. \\
& \mathrm{d}\left(A_{\mathrm{i}}, \tilde{\alpha}^{-}\right)=\frac{1}{2} \sum_{\mathrm{j}=1}^{\mathrm{m}} \mathrm{w}_{\mathrm{j}}\left[2-\left(\mathrm{v}_{\mathrm{ij}}^{\mathrm{L}}+\mathrm{v}_{\mathrm{ij}}^{\mathrm{U}}\right]\right.
\end{aligned}
$$

Where $\tilde{r}_{i j}=\left(\left[\begin{array}{cc}\mathrm{L} & \mathrm{U} \\ \mu_{\mathrm{ij}}, \mu_{\mathrm{ij}}\end{array}\right],\left[\begin{array}{cc}\mathrm{L} & \mathrm{U} \\ \mathrm{V}_{\mathrm{ij}}, \mathrm{V}_{\mathrm{ij}}\end{array}\right],\left[\begin{array}{cc}\mathrm{L} & \mathrm{U} \\ \pi_{\mathrm{ij}}, \pi_{\mathrm{ij}}\end{array}\right]\right) i=1,2, \ldots, n, \mathrm{j}=1,2, \ldots m$.

Step 6. Calculate the closeness coefficient of each alternative:

$$
c\left(A_{i}\right)=\frac{d\left(A_{i}, \tilde{\alpha}^{-}\right)}{d\left(A_{i}, \tilde{\alpha}^{+}\right)+d\left(A_{i}, \tilde{\alpha}^{-}\right)}, i=1,2, \ldots, n
$$

Step 7. Rank the alternatives according to decreasing values of closeness coefficient.

\section{Order Fulfillment Performance Evaluation}

In this section, order fulfillment performances of three companies are evaluated by using uncertain dynamic intuitionistic fuzzy evaluation. A furniture 
company operates e-commerce activities in a famous e-commerce web site in Turkey. The company has three different sub-contractors and when the order has come from the website, the company directs the order to the companies according to the volume of order. The company wants to decrease the number of sub-contractor and wants to use just one instead of using three sub-contractors. Therefore, the company needs to evaluate the sub-contractors' order fulfillment performance.

Step 1. The company uses seven different criteria in order to assess the sub-contractors as follows [1]; Generate and communicate order $\left(C_{1}\right)$, enter order $\left(C_{2}\right), \quad$ process order $\left(C_{3}\right), \quad$ handle documentation $\left(C_{4}\right)$, fill order $\left(C_{5}\right)$, deliver order $\left(C_{6}\right)$, perform post-delivery activities $\left(C_{7}\right)$.

The weight vector of the months is $\lambda(\mathrm{t})=(0.1,0.3,0.6)^{T}$ and $w=(0.1,0.1,0.2,0.1,0.2,0.2,0.1)^{T}$ is weight vector of the criteria, these weights are determined by the evaluation committee.

Step 2. Evaluation committee assesses the alternative with seven criteria by IVIFNs for three different periods. Table 1-3 show the evaluation matrices.

Step 3. Then, these matrices are aggregated in to complex decision matrix by Eq. (4) (see in Table 4).

Step 4. Define $\tilde{\alpha}^{+}, \tilde{\alpha}^{-}$, and the alternatives $A_{i}(i=1,2,3)$. We define them as follows:

$$
\begin{gathered}
\tilde{\alpha}^{+}=\left(\begin{array}{l}
([1,1],[0,0],[0,0]),([1,1],[0,0],[0,0]), \\
([1,1],[0,0],[0,0]),([1,1],[0,0],[0,0]), \\
([1,1],[0,0],[0,0]),([1,1],[0,0],[0,0]), \\
([1,1],[0,0],[0,0])
\end{array}\right)^{T} \\
\tilde{\alpha}^{-}=\left(\begin{array}{l}
([0,0],[1,1],[0,0]),([0,0],[1,1],[0,0]), \\
([0,0],[1,1],[0,0]),([0,0],[1,1],[0,0]), \\
([0,0],[1,1],[0,0]),([0,0],[1,1],[0,0]), \\
([0,0],[1,1],[0,0])
\end{array}\right)^{T} \\
\mathrm{~A}_{1}=\left(\begin{array}{l}
([0.35,0.56],[0.22,0.33],[0.11,0.42]), \\
([0.24,0.38],[0.22,0.33],[0.27,0.53]), \\
([0.50,0.62],[0.23,0.36],[0.20,0.25]), \\
([0.38,0.51],[0.21,0.34],[0.14,0.39]), \\
([0.56,0.68],[0.15,0.27],[0.03,0.28]), \\
([0.46,0.70],[0.16,0.29],[0.00,0.37]), \\
([0.37,0.53],[0.20,0.31],[0.15,0.41])
\end{array}\right)^{T}
\end{gathered}
$$

$$
\mathrm{A}_{2}=\left(\begin{array}{l}
([0.50,0.62],[0.20,0.32],[0.05,0.29]), \\
([0.29,0.39],[0.17,0.28],[0.32,0.53]), \\
([0.61,0.73],[0.13,0.24],[0.02,0.25]), \\
([0.32,0.57],[0.27,0.37],[0.04,0.40]), \\
([0.56,0.67],[0.13,0.32],[0.00,0.30]), \\
([0.44,0.60],[0.22,0.33],[0.06,0.33]), \\
([0.38,0.56],[0.20,0.30],[0.12,0.40])
\end{array}\right)^{T}=\left(\begin{array}{l}
([0.42,0.61],[0.28,0.38],[0.00,0.29]), \\
([0.27,0.42],[0.28,0.44],[0.12,0.43]), \\
([0.53,0.68],[0.15,0.26],[0.05,0.31]), \\
([0.24,0.34],[0.33,0.50],[0.15,0.42]), \\
([0.26,0.38],[0.00,0.47],[0.13,0.73]), \\
([0.55,0.65],[0.22,0.33],[0.00,0.22]), \\
([0.57,0.68],[0.16,0.31],[0.00,0.26])
\end{array}\right)^{T}
$$

Step 5. Calculate the distance between the alternative $A_{i}$ and the uncertain intuitionistic fuzzy ideal solution, and the distance between $A_{i}$ and intuitionistic fuzzy negative ideal solution. The obtained results are as follows:

$$
\begin{aligned}
& \mathrm{d}\left(A_{1}, \tilde{\alpha}^{+}\right)=0.51 \mathrm{~d}\left(A_{2}, \tilde{\alpha}^{+}\right)=0.49 \mathrm{~d}\left(A_{3}, \tilde{\alpha}^{+}\right)=0.53 \\
& \mathrm{~d}\left(A_{1}, \tilde{\alpha}^{-}\right)=0.74 \mathrm{~d}\left(A_{2}, \tilde{\alpha}^{-}\right)=0.73 \mathrm{~d}\left(A_{3}, \tilde{\alpha}^{-}\right)=0.69
\end{aligned}
$$

Step 6. Calculate the closeness coefficient of each alternative. The obtained results are as follows:

$$
c\left(A_{1}\right)=0.593 \quad c\left(A_{2}\right)=0.599 \quad c\left(A_{3}\right)=0.567
$$

Step 7. Rank the alternatives according to the values of closeness coefficient. The result is as follows:

$$
A_{2} \succ A_{1} \succ A_{3}
$$

According to the values of closeness coefficient has $A_{2}$ the highest score.

\section{Sensitivity Analysis}

In this section, a sensitivity analysis is performed. Different weights were assigned to criteria and are analyzed to observe how much it would influence the final scores of alternatives. In the first case, we assign weights as follows; $w=\left(0.7,0.05,0.05,0.05,0.05,0.05,0.05^{5}\right)$, and the ranking of alternatives is $A_{2} \succ A_{3} \succ A_{1}$. Then we change the weights of criteria as follows; $w=(0.05,0.05,0.05,0.7,0.05,0.05,0.05)^{T}$ and the ranking is $A_{1} \succ A_{2} \succ A_{3}$. 


\begin{tabular}{lllll}
\hline & $C_{1}$ & $C_{2}$ & $C_{3}$ & $C_{4}$ \\
\hline$A_{1}$ & $([0.2,0.3],[0.4,0.5],[0.2,0.4])$ & $([0.3,0.5],[0.2,0.4],[0.1,0.5])$ & $([0.4,0.6],[0.3,0.4],[0.0,0.3])$ & $([0.1,0.2],[0.4,0.5],[0.3,0.5])$ \\
$A_{2}$ & $([0.4,0.6],[0.2,0.3],[0.1,0.4])$ & $([0.2,0.3],[0.4,0.5],[0.2,0.4])$ & $([0.5,0.6],[0.2,0.4],[0.0,0.3])$ & $([0.2,0.3],[0.5,0.6],[0.1,0.3])$ \\
$A_{3}$ & $([0.3,0.4],[0.5,0.6],[0.0,0.2])$ & $([0.4,0.5],[0.2,0.3],[0.2,0.4])$ & $([0.6,0.7],[0.1,0.3],[0.0,0.3])$ & $([0.3,0.4],[0.2,0.3],[0.3,0.5])$ \\
\hline & $C_{5}$ & $C_{6}$ & $C_{7}$ & \\
\hline$A_{1}$ & $([0.4,0.6],[0.1,0.3],[0.1,0.5])$ & $([0.1,0.3],[0.5,0.6],[0.1,0.0])$ & $([0.4,0.5],[0.3,0.5],[0.0,0.3])$ & \\
$A_{2}$ & $([0.5,0.7],[0.2,0.3],[0.0,0.3])$ & $([0.5,0.6],[0.2,0.4],[0.0,0.0])$ & $([0.2,0.4],[0.3,0.4],[0.2,0.5])$ & \\
$A_{3}$ & $([0.5,0.7],[0.0,0.1],[0.2,0.5])$ & $([0.2,0.3],[0.5,0.6],[0.1,0.0])$ & $([0.2,0.3],[0.5,0.6],[0.1,0.3])$ & \\
\hline
\end{tabular}

Table 1: Decision matrix $\tilde{R}_{\left(t_{1}\right)}$ for the first period

\begin{tabular}{lllll}
\hline & $C_{1}$ & $C_{2}$ & $C_{3}$ & $C_{4}$ \\
\hline$A_{1}$ & $([0.6,0.7],[0.1,0.2],[0.1,0.3])$ & $([0.3,0.5],[0.3,0.4],[0.1,0.4])$ & $([0.3,0.4],[0.3,0.5],[0.1,0.4])$ & $([0.2,0.4],[0.2,0.4],[0.2,0.6])$ \\
$A_{2}$ & $([0.3,0.4],[0.2,0.4],[0.2,0.5])$ & $([0.3,0.4],[0.4,0.5],[0.1,0.3])$ & $([0.4,0.6],[0.2,0.3],[0.1,0.4])$ & $([0.2,0.3],[0.4,0.5],[0.2,0.4])$ \\
$A_{3}$ & $([0.5,0.7],[0.2,0.3],[0.0,0.3])$ & $([0.5,0.6],[0.3,0.4],[0.0,0.2])$ & $([0.7,0.8],[0.1,0.2],[0.0,0.2])$ & $([0.3,0.4],[0.5,0.6],[0.0,0.2])$ \\
\hline & $C_{5}$ & $C_{6}$ & $C_{7}$ & \\
\hline$A_{1}$ & $([0.2,0.3],[0.4,0.5],[0.2,0.4])$ & $([0.2,0.5],[0.3,0.5],[0.0,0.5])$ & $([0.5,0.6],[0.2,0.3],[0.1,0.3])$ & \\
$A_{2}$ & $([0.5,0.6],[0.2,0.4],[0.0,0.3])$ & $([0.5,0.6],[0.3,0.4],[0.0,0.2])$ & $([0.4,0.7],[0.2,0.3],[0.0,0.4])$ & \\
$A_{3}$ & $([0.3,0.4],[0.3,0.5],[0.1,0.4])$ & $([0.7,0.8],[0.1,0.2],[0.0,0.2])$ & $([0.3,0.4],[0.3,0.6],[0.0,0.4])$ & \\
\hline
\end{tabular}

Table 2: Decision matrix $\tilde{R}_{(t)}$ for the second period

\begin{tabular}{|c|c|c|c|c|}
\hline & $C_{1}$ & $C_{2}$ & $C_{3}$ & $C_{4}$ \\
\hline$A_{1}$ & $([0.2,0.5],[0.3,0.4],[0.1,0.5])$ & $([0.2,0.3],[0.2,0.3],[0.4,0.6])$ & $([0.6,0.7],[0.2,0.3],[0.0,0.2])$ & $([0.5,0.6],[0.2,0.3],[0.1,0.3])$ \\
\hline$A_{2}$ & $([0.6,0.7],[0.2,0.3],[0.0,0.2])$ & $([0.3,0.4],[0.1,0.2],[0.4,0.6])$ & $([0.7,0.8],[0.1,0.2],[0.0,0.2])$ & $([0.4,0.7],[0.2,0.3],[0.0,0.4])$ \\
\hline \multirow[t]{2}{*}{$A_{3}$} & $([0.4,0.6],[0.3,0.4],[0.0,0.3])$ & $([0.1,0.3],[0.3,0.5],[0.2,0.6])$ & $([0.4,0.6],[0.2,0.3],[0.1,0.4])$ & $([0.2,0.3],[0.3,0.5],[0.2,0.5])$ \\
\hline & $C_{5}$ & $C_{6}$ & $C_{7}$ & \\
\hline$A_{1}$ & $([0.7,0.8],[0.1,0.2],[0.0,0.2])$ & $([0.6,0.8],[0.1,0.2],[0.0,0.3])$ & $([0.3,0.5],[0.2,0.3],[0.2,0.5])$ & \\
\hline$A_{2}$ & $([0.6,0.7],[0.1,0.3],[0.0,0.3])$ & $([0.4,0.6],[0.2,0.3],[0.1,0.4])$ & $([0.4,0.5],[0.2,0.3],[0.2,0.4])$ & \\
\hline$A_{3}$ & $([0.2,0.3],[0.4,0.6],[0.1,0.4])$ & $([0.5,0.6],[0.3,0.4],[0.0,0.2])$ & $([0.7,0.8],[0.1,0.2],[0.0,0.2])$ & \\
\hline
\end{tabular}

Table 3: Decision matrix $R_{\left(t_{3}\right)}$ for the third period

\begin{tabular}{lllll}
\hline & $C_{1}$ & $C_{2}$ & $C_{3}$ & $C_{4}$ \\
\hline$A_{1}$ & $([0.35,0.55],[0.22,0.33],[0.11,0.42])$ & $([0.24,0.38],[0.22,0.33],[0.27,0.53])$ & $([0.50,0.62],[0.23,0.36],[0.02,0.25])$ & $([0.38,0.51],[0.21,0.34],[0.14,0.39])$ \\
$A_{2}$ & $([0.50,0.62],[0.20,0.32],[0.05,0.29])$ & $([0.29,0.39],[0.17,0.28],[0.32,0.53])$ & $([0.61,0.73],[0.13,0.24],[0.02,0.25])$ & $([0.32,0.57],[0.27,0.37],[0.04,0.40])$ \\
$A_{3}$ & $([0.42,0.61],[0.28,0.38],[0.00,0.29])$ & $([0.27,0.42],[0.28,0.44],[0.12,0.43])$ & $([0.53,0.68],[0.15,0.26],[0.05,0.31])$ & $([0.24,0.34],[0.33,0.50],[0.15,0.42])$ \\
\hline & $C_{5}$ & $C_{6}$ & $C_{7}$ & \\
\hline$A_{1}$ & $([0.56,0.68],[0.15,0.27],[0.03,0.28])$ & $([0.46,0.70],[0.16,0.29],[0.00,0.37])$ & $([0.37,0.53],[0.20,0.31],[0.15,0.41])$ & \\
$A_{2}$ & $([0.56,0.67],[0.13,0.32],[0.00,0.30])$ & $([0.44,0.60],[0.22,0.33],[0.06,0.33])$ & $([0.38,0.56],[0.20,0.30],[0.12,0.40])$ & \\
$A_{3}$ & $([0.26,0.38],[0.00,0.47],[0.13,0.73])$ & $([0.55,0.65],[0.22,0.33],[0.00,0.22])$ & $([0.57,0.68],[0.16,0.31],[0.05,0.26])$ & \\
\hline
\end{tabular}

Table 4: Complex decision matrix $\tilde{R}$ 
We assigned the weights as follows; $w=(0.05,0.05,0.05,0.05,0.05,0.7,0.05)^{T}$ and the ranking of alternatives is $A_{1} \succ A_{3} \succ A_{2}$. At last, we change the weights of criteria as follows; $w=(0.05,0.05,0.05,0.05,0.05,0.05,0.7)^{T}$ and the ranking is $A_{3} \succ A_{2} \succ A_{1}$. According to the sensitivity analysis results, the best alternative decision is insensitive to the changes in the criteria weights. Figure 1 shows the results of sensitivity analysis.

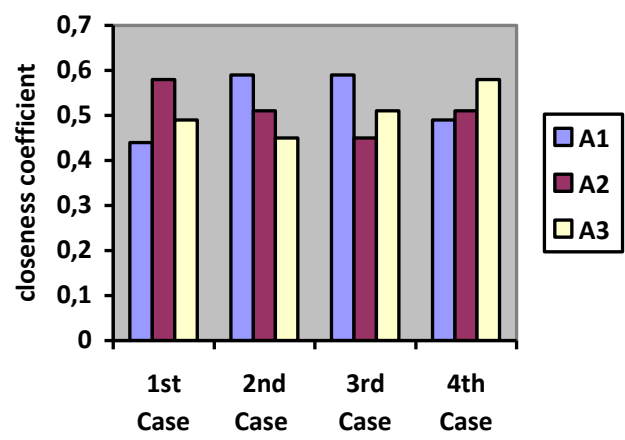

Figure 1. Sensitivity Analysis

\section{Conclusion}

In this study, we evaluate three different firms' order fulfillment performance by using uncertain dynamic intuitionistic fuzzy multi-attribute decision making method.

Order fulfillment process is one of the main key processes of the supply chain management. Customers prefer firms working with fast delivery, it means using less time in delivery process in supply chain management gives advantages to firms. Order fulfillment process can be dived in seven categories as follows; Generate and communicate order, enter order, process order, handle documentation, fill order, deliver order, perform post-delivery activities.

In this study, we evaluate the firms according to these categories by interval valued intuitionistic fuzzy numbers for three different periods in a year. Then, we rank them according to decreasing values of closeness coefficient. The uncertain dynamic intuitionistic MADM can handle the problem effectively. The method has advantages because of collecting decisions which are made in different periods.

As for future work, other intuitionistic fuzzy MADM methods like intuitionistic AHP, intuitionistic ANP, intuitionistic VIKOR can be used in evaluating order fulfillment and can be compared with the finding of the current study.

\section{References}

[1] D.M. Lambert, Supply Chain Management Process, Partnership, Performance, Florida, 2008.

[2] P. Shapiro, Benson, V. Kasturi Rangan, J. J. Sviokla, Staple Yourself to an Order Harvard Business Review, Vol. 40, No. 4 1992, pp.113122.

[3] E. K. Zavadskas, J. Antucheviciene, S. H. R. Hajiagha, S. S. Hashemi, Extension of weighted aggregated sum product assessment with interval valued intuitionistic fuzzy numbers (WASPASIVIF), Applied Soft Computing, Vol. 24, 2014, pp.1013-1021.

[4] I. Linkov, F.K. Satterstrom, J. Steevens, E. Ferguson, R.C.Pleus, Multicriteria decision analysis and Enviromental risk assesment for nanomaterials, J. Nanopart. Res. Vol.9 2007, 543-554.

[5] S. Dadelo, Z. Turskis,, E. K. Zavadskas, R. Dadeliene, Multi-criteria assessment and ranking system of sport team formation based on objective measured values of criteria set. Expert Systems with Applications, Vol.41 2014, 61066113.

[6] D. Streimikiene, T. Balezentis, I. Krisciukaitiene, A. Balezentis, Prioritizing sustainable electricity production technologies: MCDM approach. Renewable and Sustainable Energy Reviews, Vol.16 2012, pp.3302-3311.

[7] D. Wittstruck, F. Teuteberg, Integrating the concept of sustainability into the partner selection process: a fuzzy-AHP-TOPSIS approach, Int J Logist Syst Manage Vol. 12, No. 2 2012, pp. 195-226.

[8] P. Ghadimi, A. Dargi, C. Heavey, Making sustainable sourcing decisions: practical evidence from the automotive industry. Int $\mathbf{J}$ Logist, Vol. 20 No. 4 2017, 297-321.

[9] L. A. Zadeh, Fuzzy sets. Information and Control,1965, 8, pp. 338-353

[10] L. Abdullah, L. Najib, A new preference scale of intuitionistic fuzzy analytic hierarchy process in multi-criteria decision making problems, Journal of Intelligent and Fuzzy Systems, 262014 pp. 1039-1049.

[11] S. Kubler, A. Voisin, W. Derigent, A. Thomas, E. Rondeau, K. Framling, Group fuzzy AHP approach to embed relevant data on "communicating material", Computers in Industry, 652014 pp.675-692.

[12] K. Devi, S. P. Yadav, A multicriteria intuitionistic fuzzy group decision making for plant location selection with ELECTRE method, The International Journal of Advanced Manufacturing Technology, 66 2013,pp. 12191229. 
[13] M. Kabak, E.Kose, O. Kırılmaz, S. Burmaoglu, A fuzzy multi-criteria decision making approach to assess building energy performance, Energy and Buildings, 72 2014, 382-389.

[14] G. A. Keskin, Using integrated fuzzy DEMATEL and fuzzy C: Means algorithm for supplier evaluation and selection, International Journal of Production Research, 2014, 1-17.

[15] Y. J. Wang, A fuzzy multi-criteria decisionmaking model by associating technique for order preference by similarity to ideal solution with relative preference relation, Information Sciences, 268 2014, 169-184.

[16] K. T., Atanassov, Intuitionistic Fuzzy Sets. Fuzzy Sets and Systems, 201986 87-96.

[17] P. Liu, Some hamacher aggregation operators based on the interval-valued intuitionistic fuzzy numbers and their application to group decision making, IEEE Transactions on Fuzzy Systems, 22 2014, 83-97.

[18] H. Liao, Z. Xu, Priorities of intuitionistic fuzzy preference relation based on multiplicative consistency, IEEE Transactions on Fuzzy Systems, 22 2014, 1669-1681.

[19] Q. Lei, Z. Xu, Derivative and differential operations of intuitionistic fuzzy numbers, International Journal of Intelligent Systems, 30 2015, 468-498.

[20] Z. Xu, R.R. Yager, Dynamic Intuitionistic fuzzy multi-attribute decision making. International Journal of Approximate Reasoning 482008 246262. 